Ahmet Mustafa Erer
Karabük University, mustafaererekarabuk.edu.tr, Karabük-Turkey

\begin{tabular}{l|l}
\hline DOI & http://dx.doi.org/10.12739/NWSA.2017.12.4.2A0123 \\
\hline ORCID ID & $0000-0003-4358-4010$ \\
\hline \hline
\end{tabular}

\title{
WETTING BEHAVIORS AND INTERFACIAL PROPERTIES OF SAC300, SAC305 AND SAC0307 TERNARY Pb-FREE SOLDER ALLOYS
}

\section{ABSTRACT}

The wetting behavior and interfacial properties of molten SAC300, SAC305 and SAC0307 (Sn-Ag-Cu) Pb-free solder alloys were investigated by sessile drop technique at various temperatures (250, 280 and $310^{\circ} \mathrm{C}$ ) on $\mathrm{Cu}$ substrate in Ar atmosphere, as well as its dependence on time. The contact angles of the Pb-free solder alloys on $\mathrm{Cu}$ substrate do not decrease sharply with increasing temperature but change with time. The contact angles were measured for SAC305, SAC300 and SAC0307 alloys and the lowest $\theta$ was obtained as $41.90^{\circ}$ for SAC305 alloy at $310^{\circ} \mathrm{C}$. The melting temperatures were examined which for SAC305 Pb-free alloy is lower than those for SAC300, SAC0307 Pb-free alloys. The formation of intermetallic compounds (IMC) between the $\mathrm{Pb}-$ free solder alloys and the Cu substrate was observed.

Keywords: Pb-free Solder Alloy, Contact Angle, Sessile Drop Technique, IMC

\section{INTRODUCTION}

Due to polluting effects on environment and harming human health, the electronics industry is also enforced by RoHS directive of European Union to reduce the usage of toxic substances [1]. Because of the toxicity of the traditional $\mathrm{Sn}-\mathrm{Pb}$ solder alloy, researchers have actuated widely to find alternative Pb-free solder alloys especially suitable for electronics industry [2]. The solders with high-melting temperatures are effectively used in electronics industry and device manufacturing [3]. In modern microelectronic technology, soldering playsan important role. In both of circuit-board and flip-chip technologies, solder is used to connect apparatus to printed-circuit boards. In the soldering process, the molten solder and metal surface are connected to each other with a metallurgical bond [4]. Thus, the ability of molten solder alloys to flow or spreading on the solid metal surface is important for the formation of healthymetallurgical bond. The phenomenon of liquid spreading on a solid surface is also referred as wetting. In fact that, wettability is defined as the tendency for liquid to spread on a solid surface [4 and 6]. The solderability is directly related to the wettability of two surfaces being joined. The efficiency of manufacturing and reliability of electronic devices depend upon the quality of solderability thus wettability [7]. Wettability generally involves the measurement of contact angles as the primary data, which specifies the degree of wetting when a solid and liquid interact. Thus, the measurement of the contact angle gives an estimate on wetting behaviour. To determine the wettability of a solid metal substrate by molten solder alloy, Young's equation is conventionally used:

$$
\cos \theta=\gamma_{\mathrm{SV}}-\gamma_{\mathrm{SL}} / \gamma_{\mathrm{LV}}
$$


where $\theta$ is the contact angle in degree; $\gamma_{\text {sv }}$ is the surface tension of the solid-vapour; $\gamma_{\mathrm{SL}}$ is the surface tension between the liquid and the solid; $\gamma_{\mathrm{LV}}$ is the surface tension of the liquid-vapour. A small contact angle $\left(<90^{\circ}\right)$ corresponds to high wettability, while the large contact angle $\left(>90^{\circ}\right)$ corresponds to low wettability [8]. A $\mathrm{Pb}$-free solder alloy drop spreads to enlarge on the $\mathrm{Cu}$ substrate and comes to rest making an angle. Under equilibrium conditions this angle is called contact angle which is decided by the surface and interfacial tensions. It is usually accepted that the smaller the contact angle, the better the wettability. The process of wetting and spreading includes the flow of fluid over the surface of a solid. That flow is influenced by number of factors such as viscosity, work of adhesion, melting temperature, thickness of intermetallic compounds (IMCs), surface tension and spreading, etc [9]. The formation and growth of IMCs between molten solder alloy and substrate have influence on the efficiency of Pb-free solder alloys [10]. In order to attain perfect wettability of $\mathrm{Pb}$-free solder alloys as substitutes for $\mathrm{Sn}-\mathrm{Pb}$ solder alloys, $\mathrm{Sn}-\mathrm{Ag}-\mathrm{Cu} \mathrm{Pb}-\mathrm{free}$ alloy systems have been studied in the previous works $[1,5,6,9,11,13,16,18,20,21$, and 23]. However, the effects of contact angles and interfacial reactions on wettability must also be compared. The purpose of this work is to investigate and to compare the wettability of SAC300, SAC305 and SAC0307 Pb-free solder alloys on $\mathrm{Cu}$ substrate in Atmosphere at various temperatures 250,280 and $310^{\circ} \mathrm{C}$.

\section{RESEARCH SIGNIFICANCE}

Wetting behaviours of SAC300, SAC305 and SAC0307 Pb-free solder alloys on $\mathrm{Cu}$ substrate were investigated by these sessile drop technique in Ar atmosphere. Interfacial properties were also investigated for the Pb-free solder alloys. It was seen that two intermetallic layers $\left(\mathrm{Cu}_{6} \mathrm{Sn}_{5}\right.$ and $\left.\mathrm{Cu}_{3} \mathrm{Sn}\right)$ were commonly found at the interfacial zone of $\mathrm{Sn}-\mathrm{Ag}-\mathrm{Cu} \mathrm{Pb}$-free solder alloys and the $\mathrm{Cu}$ substrate. Accordingto DSC analysis results, SAC305 alloy has the lowest melting temperature $\left(217,8{ }^{\circ} \mathrm{C}\right)$ than other alloys. The experimental results showed that equilibrium contact angles ( $(\theta)$ proportionally decreased with increasing temperature and time. The lowest $\theta$ was obtained as $41,90^{\circ}$ for SAC305 alloy at $310{ }^{\circ} \mathrm{C}$. Thus, the SAC305 alloy exhibits better wetting behaviour than the SAC 300 and SAC0307 alloys.

\section{MATERIALS, EXPERIMENTAL PROCEDURES AND METHOD}

In this study, SAC300, SAC305 and SAC0307 Pb-free solder alloys and oxygen-free $\mathrm{Cu}$ were chosen as the soldering materials and the substrate, respectively. The chemical compositions of the studied $\mathrm{Pb}-$ free solder alloys are listed in Table 1.

Table 1. Chemical composition of $\mathrm{Pb}$-free solder alloys (wt. ㅇ)

\begin{tabular}{|l|c|c|c|c|c|c|c|}
\hline Pb-free alloys & $\mathrm{Ag}$ & $\mathrm{Cu}$ & $\mathrm{Sb}$ & $\mathrm{Bi}$ & $\mathrm{Pb}$ & $\mathrm{As}$ & $\mathrm{Sn}$ \\
\hline SAC300 & 3.05 & 0.05 & 0.12 & 0.1 & 0.1 & 0.03 & Rest \\
\hline SAC305 & 2.98 & 0.52 & 0.1 & 0.1 & 0.1 & 0.03 & Rest \\
\hline SAC0307 & 0.35 & 0.73 & 0.05 & 0.05 & 0.1 & 0.01 & Rest \\
\hline
\end{tabular}

The sessile drop technique was used in the wettability testing's [2 and 13]. By means of this technique, the SAC300, SAC305 and SAC0307 solder alloy was dropped on copper substrate at various temperatures of 250, 280 and $310^{\circ} \mathrm{C}$. Casio Pro EX-F1 (1200 fps) Model camera used to catch views of drops at the 5th, 10th, 15th, 30th, 60th, 90th, 120th, and 150 th seconds and these images were transferred into AutoCAD 2010 to measure contact angles of each drop from the right and left profiles [11]. As a result of these processes repeated for each 
temperature, mean angle values were calculated and new diagrams were drawn through the Sigma Plot 12.0 software. Standard metallographic processes were carried out for microstructure examinations. Prepared specimens were etched with $100 \mathrm{ml} \mathrm{H}_{2} \mathrm{O}, 2 \mathrm{ml} \mathrm{HCl}, 10 \mathrm{~g} \mathrm{FeCl} 3$ solution for $45 \mathrm{~s}$. The etched specimens were characterized by the scanning electron microscope and energy dispersive X-ray spectroscopy (SEM+EDS) and Xray diffraction (XRD). In order to determine melting temperatures of alloys, the DSC analysis were carried out on specimens in maximum $30 \mathrm{mg}$ weight and at $40-300^{\circ} \mathrm{C}$ temperature range (5 min). The morphology of the interface of $\mathrm{Sn}-\mathrm{Ag}-\mathrm{Cu} / \mathrm{Cu}$ was also analysed.

\section{RESULTS AND DISCUSSIONS}

\subsection{Temperature effects on contact angle}

Figure 1 shows the relationship between the contact angle and the temperature and the time. For SAC300, SAC305 and SAC0307 Pb-free solder alloys, the contact angle does not decrease suddenly with temperature but changes with time. A sharp decrease in the contact angle is observed for the Pb-free solder alloys at each temperature for approximately the first $30 \mathrm{~s}$. The values of contact angle exhibit the degree of wettability [14]. Table 2 lists the equilibrium contact angles of the SAC305 Pb-free solder alloy on $\mathrm{Cu}$ substrate at each temperature for the present work and for the others reported elsewhere.
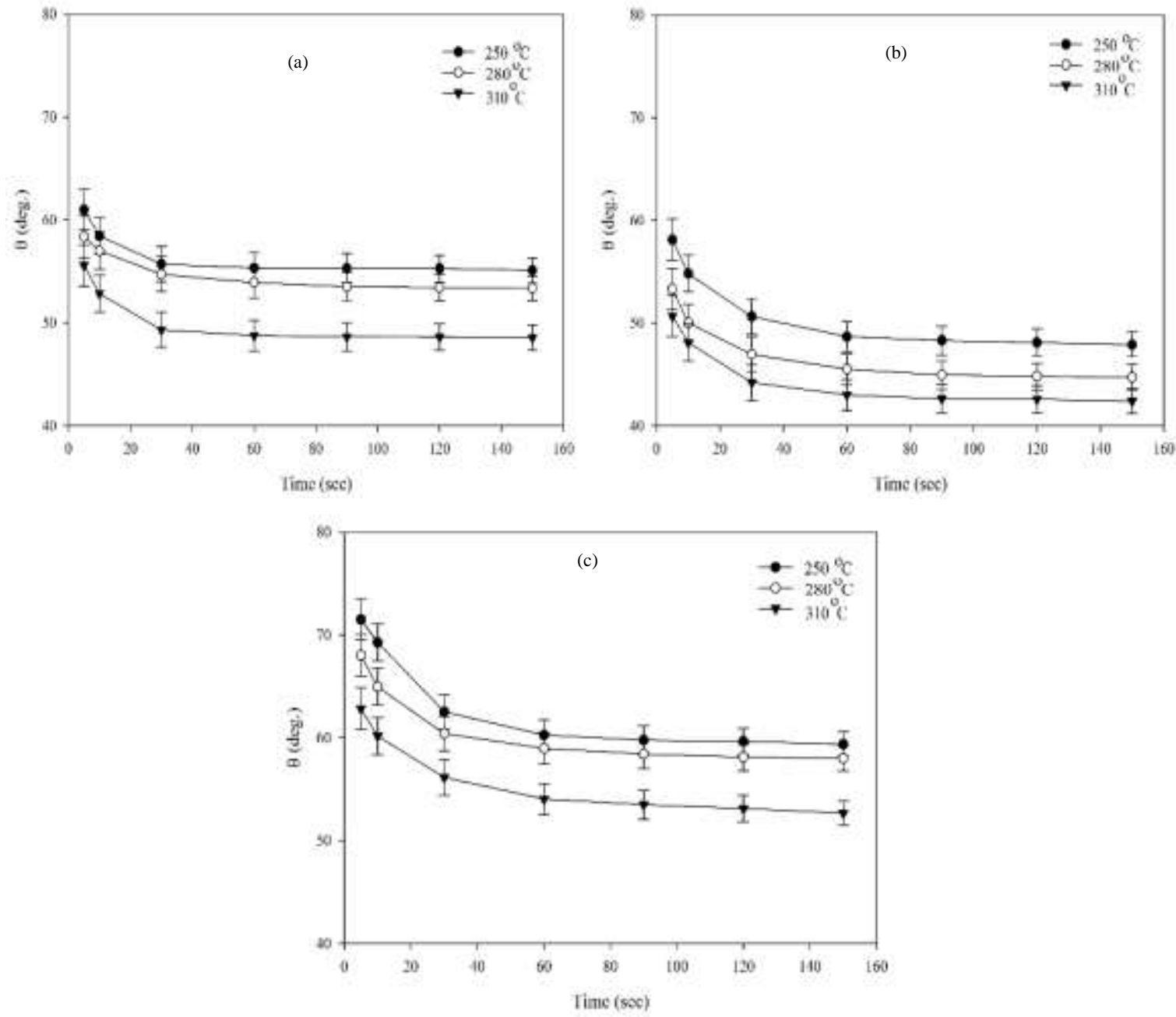

Figure 1. Time dependence of the contact angle of molten Pb-free solder alloys on Cu substrate at various temperatures for (a) SAC300, (b) SAC305 and (c) SAC0307 
Erer, A.M.

Technological Applied Sciences (NWSATAS), 2A0123, 2017; 12(4):163-169.

Table 2. The equilibrium contact angles of SAC305 Pb-free solder alloy on $\mathrm{Cu}$ substrate at each temperature

\begin{tabular}{|c|c|c|c|c|c|c|c|c|c|}
\hline Pb-free Alloy & \multicolumn{8}{|c|}{ Contact Angle } & \multirow{2}{*}{ Ref. } \\
\hline \multirow{5}{*}{ SAC305 } & $217^{\circ} \mathrm{C}$ & $230^{\circ} \mathrm{C}$ & $250^{\circ} \mathrm{C}$ & $280^{\circ} \mathrm{C}$ & $300^{\circ} \mathrm{C}$ & $310^{\circ} \mathrm{C}$ & $350^{\circ} \mathrm{C}$ & $400^{\circ} \mathrm{C}$ & \\
\hline & $53.5^{\circ}$ & - & - & - & - & - & - & & 10 \\
\hline & - & $32.5^{\circ}$ & $29.3^{\circ}$ & - & $27.3^{\circ}$ & - & - & $26.65^{\circ}$ & 15 \\
\hline & $53.5^{\circ}$ & - & $49.6^{\circ}$ & - & $47.2^{\circ}$ & - & $47.2^{\circ}$ & - & 16 \\
\hline & - & - & $49.1^{\circ}$ & $45.1^{\circ}$ & - & $41.9^{\circ}$ & - & - & P.Work \\
\hline
\end{tabular}

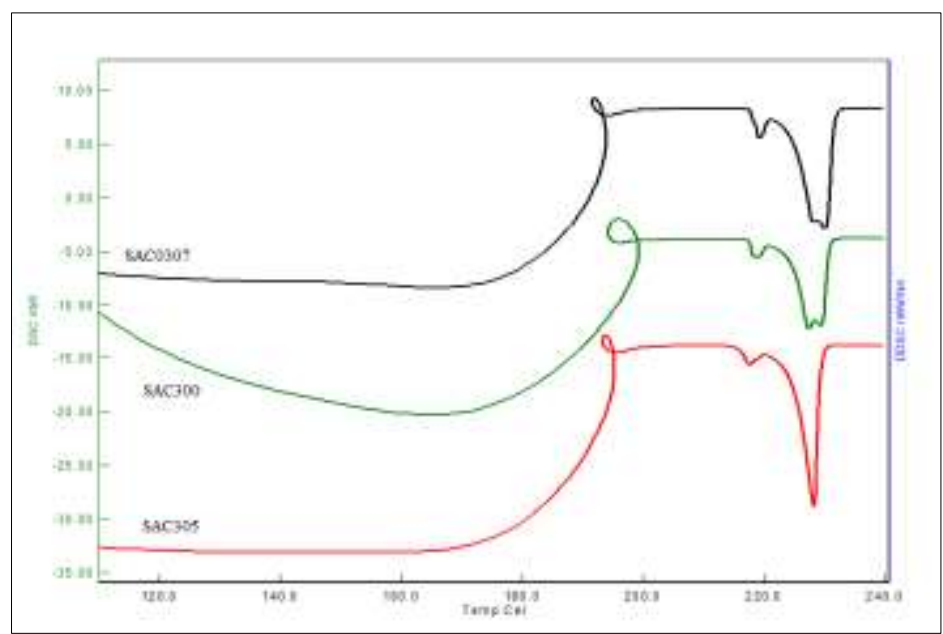

Figure 2. DSC analysis results of SAC300, SAC0307 and SAC305 alloys

Figure 2 shows DSC analysis results of SAC300, SAC0307 and SAC305 alloys. As can be seen from Figure 2 that the melting temperature of SAC305 is lower than those of SAC300 and SAC0307. Besides, due to its lowest melting temperature $\left(217.8^{\circ} \mathrm{C}\right)[10,12,15$, and 22], SAC305 has the longest wetting time (90s) [12]. Thus, the wettability of SAC305 Pb-free solder alloy is better than those of SAC300 and SAC0307 Pb-free solder alloys.

\subsection{Interfacial Properties}

During the soldering process, SAC300, SAC305 and SAC0307 Pb-free solder alloys melt and get into contact with cu substrate. Furthermore, $\mathrm{Sn}$ in the molten solder alloys reacts with $\mathrm{Cu}$ to form intermetaliic compounds (IMCs)on the interface. The IMCs promote the bonding between the solder alloys and $\mathrm{Cu}$ [16 and 23].

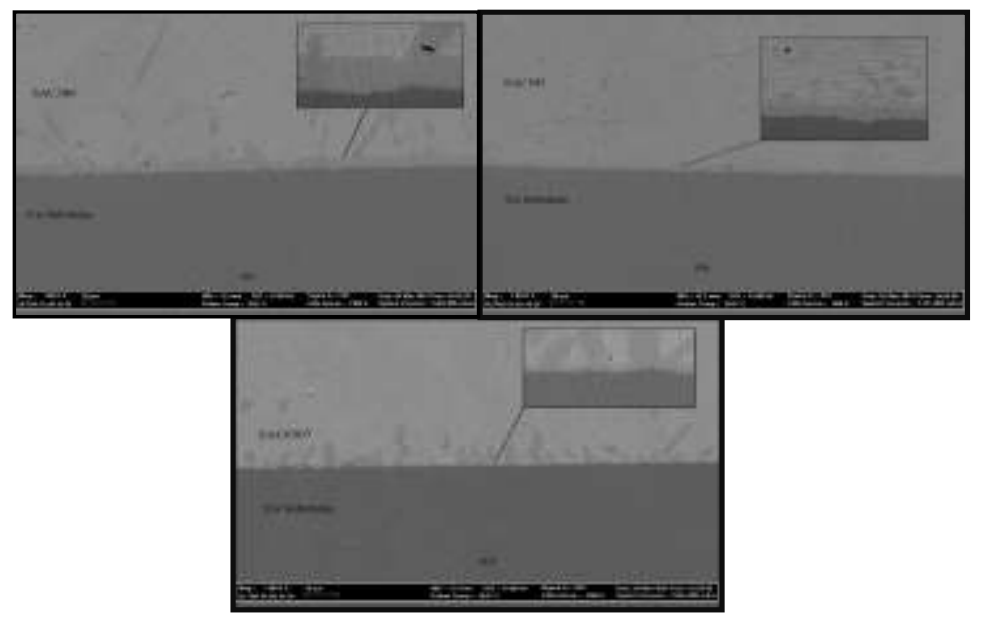

Figure3. SEM images of the $\mathrm{Pb}$-free solder/Cu interface at $310^{\circ} \mathrm{C}$ on $\mathrm{Cu}$ substrate for (a) SAC300 (b) SAC305 and (c) SAC0307 


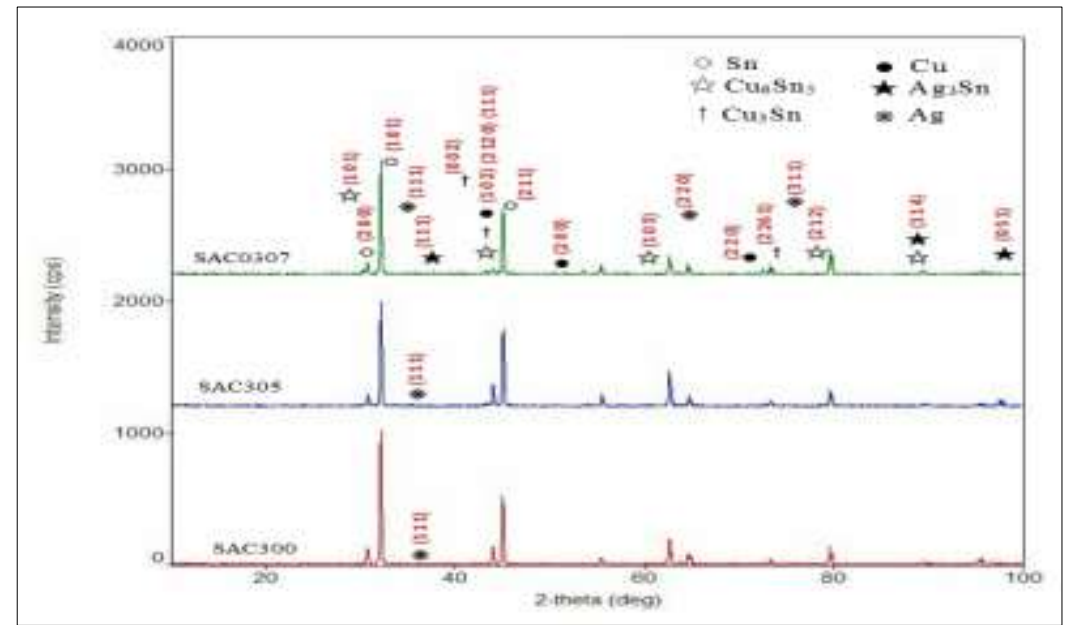

Figure4. XRD analysis results of SAC300, SAC305 and SAC0307 Alloys

From SEM and XRD analysis given in Figure $3 a-c$ and Figure 4, Cu$\mathrm{Sn}$ IMCs are seen in the Pb-free solder alloys and Cu interface. Interfacial reactions between the $\mathrm{Cu}$ substrate and the three molten Pb-free solder alloys of SAC300, SAC305 and SAC0307 lead to two types of IMCs, $\mathrm{Cu}_{6} \mathrm{Sn}_{5}$ and $\mathrm{Cu}_{3} \mathrm{Sn}$. While the $\mathrm{Cu}_{6} \mathrm{Sn}_{5}$ is adjacent to the solder alloys, the $\mathrm{Cu}_{3} \mathrm{Sn}$ is adjacent to the $\mathrm{Cu}$ substrate [4, 17 and 18]. The scallop type $\mathrm{Cu}_{6} \mathrm{Sn}_{5}$ was formed through the interfacial reactions between Sn-Ag-Cu/Cu systems. The formation of Cu-Sn IMCs is realised by the continuous growth of $\mathrm{Cu}_{6} \mathrm{Sn}_{5}$. On the other hand, the formation and growth of $\mathrm{Cu}_{3} \mathrm{Sn}$ is realised in the interface of $\mathrm{Cu}_{6} \mathrm{Sn}_{5}$ and $\mathrm{Cu}$ substrate. The formation of $\mathrm{Cu}_{3} \mathrm{Sn}$ is controlled by the phase stability according to the following reactions [19];

$$
\mathrm{Cu}_{6} \mathrm{Sn}_{5}+9 \mathrm{Cu} \longrightarrow 5 \mathrm{Cu}_{3} \mathrm{Sn}
$$

Vianco [19] reported that $\mathrm{Cu}_{6} \mathrm{Sn}_{5}$ intermetallic was formed during soldering and $\mathrm{Cu}_{3} \mathrm{Sn}$ was formed during solid-state ageing between $\mathrm{Cu}_{6} \mathrm{Sn}_{5}$ and $\mathrm{Cu}$ substrate. It is clear that the thickness of IMCs is established by the relative movement of two interfaces; IMCs/liquid solder and solid/IMCs [21]. Lee and Mohamad [21] reviewed the reactions of $\mathrm{Sn}-\mathrm{Ag}-\mathrm{Cu} / \mathrm{Cu}$ interface in detail and mentioned the importance of $\mathrm{Sn}-\mathrm{Ag}-\mathrm{Cu} \mathrm{Pb}$-free solder alloys in electronic industry. They concluded that thin, continuous and uniform IMC layers are main requirement for good bonding. Without IMCs, the solder/substrate interface is poor as metallurgical interaction does not take place in the bonding. Nevertheless, thick IMCs at the solder/substrate interface may reduce the reliability of the solder interface because of their inherent brittle nature. In addition, thick IMCs are likely to lead to structural defects which deterioratethe physical properties. Both the $\mathrm{Cu}_{6} \mathrm{Sn}_{5}$ and $\mathrm{Cu}_{3} \mathrm{Sn}$ intermetallic phases were found at the interface depending on soldering conditions. It is expected that the thickness of $\mathrm{Cu}_{3} \mathrm{Sn}$ is smaller than $\mathrm{Cu}_{6} \mathrm{Sn}_{5}$. That is because $\mathrm{Cu}_{3} \mathrm{Sn}$ is grown by solid-state diffusion. Chen et al. [23] investigated the available phase diagrams of Pb-free solders, and the materials systems including the solders and the substrates. They stated that the thick IMC layer should be avoided during the soldering. The authors concluded that increasing IMCs thickness results from increasing soldering time. Thus, the $\mathrm{Cu}_{3} \mathrm{Sn}$ thickness increases with decreasing $\mathrm{Cu}_{6} \mathrm{Sn}_{5}$ thickness despite the fact that $\mathrm{Cu}_{6} \mathrm{Sn}_{5}$ generally grows with increasing soldering time [24].

\section{CONCLUSION}

In summary, wetting behaviours of SAC300, SAC305 and SAC0307 Pbfree solder alloys on $\mathrm{Cu}$ substrate were investigated by this sessile 
drop technique in Ar atmosphere. Interfacial properties were also investigated for the Pb-free solder alloys. It was seen that two intermetallic layers $\left(\mathrm{Cu}_{6} \mathrm{Sn}_{5}\right.$ and $\left.\mathrm{Cu}_{3} \mathrm{Sn}\right)$ were commonly found at the interfacial zone of $\mathrm{Sn}-\mathrm{Ag}-\mathrm{Cu} \mathrm{Pb}-\mathrm{free}$ solder alloys and the $\mathrm{Cu}$ substrate. According to DSC analysis results, SAC305 alloy has the lowest melting temperature $\left(217.8^{\circ} \mathrm{C}\right)$ than other alloys. The experimental results showed that equilibrium contact angles $(\theta)$ proportionally decreased with increasing temperature and time. The lowest $\theta$ was obtained as $41.90^{\circ}$ for SAC305 alloy at $310^{\circ} \mathrm{C}$. Thus, the SAC305 alloy exhibits better wetting behaviour than the SAC 300 and SAC0307 alloys.

\section{ACKNOWLEDGEMENTS}

This work was supported by Scientific Research Projects Coordination Unit of Karabük University. Project Number: KBÜBAP-17-YD314 .

\section{NOTE}

This work is presented at 5-8 September 2017, $2^{\text {nd }}$ International Science Symposium (ISS2017) in Tbilisi/Georgia.

\section{REFERENCES}

1. Mookam, N. and Kanlayasiri, K., (2011). Journal of Alloys and Compounds, Vol:509, 6276-6279.

2. Erer, A.M., Candan, E., Güven, M.H., and Turen Y., (2011). European Physical Journal Applied Physics, Vol:54, 11302.

3. Plevachuk, Y., Hoyer, W., Kaban, I., Köhler, M., and Novakovic, R., (2010). Journal of Material Sciience, Vol:45, 2051-2056.

4. Arenas, M.F. and Acoff, V.L., (2004). Journal of Electronic Materials, Vol:33, No:12, pp:1452-1458.

5. Amore, S., Ricci, E., Borzone, G., and Novakovic, R., (2008). Materials Science and Engineering A, Vol:495, pp:108-112.

6. Duong, N.B., Ariga, T., Hussainand, L.B., and Ismail, A.B., (2008). Materials Transactions, Vol:49, No:6, pp:1462-1466.

7. Yoon, S.W., Choiand, W.K., and Lee, H.M., (1999). Scripta Materialia, Vol:40, No:3, pp:297-302.

8. Yuan, Y. and Lee, T.R., (2013). Surface Science Techniques, Springer Series in Surface Sciences, Vol:51, pp:3-34.

9. Kumar, G. and Prabhu, K.N., (2007). Advances in Colloid and Interface Science 133, 61-89.

10. Zhang, X., Yuan, Z., Zhao, H., Zang, L., and LI, J., (2010). Chinese Science Bulletin, Vol:55, pp:797-801.

11. Omac, F., Özyurek, D., and Erer, M., (2017). Investigation of the Wetting Properties of Ternary Lead-Free Solder Alloys on Copper Substrate, Acta Physica Polonocia- A, Vol:131.

12. Zhang, X., Matsuura, H., Tsukihashi, F., and Yuan, Z., (2012). Material Transactions, Vol:53, No:5, pp:926-931.

13. Candan, E., Atkinson, H.V., Turen, Y., Salaoru, I., and Candan, S., (2011). Journal of the American Ceramic Society, Vol:94, No:3, pp:867-874.

14. Zang, L., Yuan, Z., Xu, H., and Xu, B., (2011). Applied Surface Science, 257, 4877-4884.

15. Islam, M.N., Chan, Y.C., Rizvi, M.J., and Jillek, W., (2005). Journal of Alloys and Compounds, 400, 136-144.

16. Lee, L.M., Haliman, H., and Mohamad, A.A., (2013). Soldering\&Surface Mount Technology, vol:25, no:1, pp:15-23.

17. Liang, J., Dariavach, N., Callahan, P., and Shangguan, D., (2006). Materials Transactions, Vol:47, No:2, pp:317-325.

18. Suganuma, K., Huh, S-H., Kim, K., Nakase, H., and Nakamura, Y., (2001). Materials Transactions, Vol:42, No:2, pp:286-291. 
19. Gao, F., Takemoto, T., and Nishikawa, H., (2006). Materials Science and Engineering A, Vol:420, no:1-2, pp:39-46.

20. Vianco, P.T., (2000). Circuit World, Vol:25, no:1, pp:1207-1213.

21. Gong, J., Liu, C., Conway, P.P., and Silberschmidt, V.V., (2008). Acta Materiala, 56, 4291-4297.

22. Lee, L.M. and Mohamad, A.A., (2013). Advances in Materials Science and Engineering, Vol:2013.

23. Chen, S.W., Wang, C.H., Lin, S.K. and Chiu, C.N., (2007). Journal of Materials Science, Vol:18, no:1-3, 19-37.

24. Yu, D.Q. and Wang, L., (2008). Journal of Alloys and Compounds, Vol:458, no:1-2, 542-547. 